\title{
MICROPROPAGAÇÃO DE CITRUMELO 'SWINGLE' PELO CULTIVO IN VITRO DE GEMAS AXILARES ${ }^{1}$
}

\author{
FABRIZZIO DE SOUZA CANTAGALLO ${ }^{2}$, FERNANDO ALVES DE AZEVEDO ${ }^{3}$, EVANDRO HENRIQUE SCHINOR ${ }^{2}$, \\ FRANCISCO DE ASSIS ALVES MOURÃO FILHO ${ }^{4}$, BEATRIZ MADALENA JANUZZI MENDES ${ }^{5}$
}

\begin{abstract}
RESUMO - O uso da micropropagação na produção de mudas constitui-se em técnica de multiplicação importante, embora não seja usual para citros, cujos porta-enxertos são obtidos por sementes. Entretanto, pode ser alternativa viável quando a demanda por material propagativo for superior em relação à oferta de sementes. Buscou-se micropropagar o citrumelo 'Swingle' através de gemas axilares, excisadas de plantas cultivadas em meio MT, seis semanas após a semeadura e submetidas a combinações de 6-benzilaminapurina (BAP) $(0,0 ; 0,5 ; 1,0$ e 1,5 mg L'-1) e ácido naftaleno acético (ANA) $\left(0,0\right.$ e $\left.0,5 \mathrm{mg} \mathrm{L}^{-1}\right)$. As brotações foram enraizadas em meio RMAN para posterior aclimatização. O número de brotações induzidas foi afetado apenas pelas concentrações de BAP. Melhor desenvolvimento vegetativo foi alcançado em brotações advindas dos tratamentos com as menores concentrações de reguladores.
\end{abstract}

Termos para indexação: citros, porta-enxerto, multiplicação de brotos, cultura de tecidos.

\section{MICROPROPAGATION OF 'SWINGLE' CITRUMELO THROUGH AXILARY BUDS IN VITRO CULTURE}

ABSTRACT - The use of micropropagation to nursery tree production is considered an important technique of propagation, although it is not usual in citrus industry, where rootstocks are produced by seedlings. However, it might be a viable alternative when the demand for nursery material is higher than seed availability. This work aimed to micropropagate 'Swingle' citrumelo through axilary buds, excised from in vitro seedlings cultivated in MT medium, six weeks after seed incubation, and submitted to combinations of BAP - 6-benzilaminapurine $\left(0,0 ; 0,5 ; 1,0 \mathrm{e} 1,5 \mathrm{mg} \mathrm{L}{ }^{-1}\right)$ and NAA naftalene acetic acid $\left(0,0\right.$ e $\left.0,5 \mathrm{mg} \mathrm{L}^{-1}\right)$. Shoots were rooted in RMAN medium and then acclimated. The number of induced shoots was affected by concentrations of BAP. The best vegetative development of the acclimated plants was accomplished in shoots from treatments with lower growth regulator concentrations.

Index terms: citrus, rootstock, shoot multiplication, tissue culture.

\section{INTRODUÇÃo}

O Brasil é, atualmente, o maior produtor mundial de frutas cítricas e lidera as exportações de suco cítrico concentrado. Embora ocupe essa posição de destaque, grande parte dos pomares brasileiros está enxertada sobre limão 'Cravo' (Salva, 2001). Este porta-enxerto tornou-se predominante na citricultura brasileira, após a entrada do vírus da tristeza dos citros, por ser tolerante a esta doença (Rossetti, 1991). É parcialmente tolerante à gomose de Phytophthora (Amorim, 1997) e sensível ao declínio (Pompeu Júnior, 2001), além de apresentar características horticulturais favoráveis, como compatibilidade com grande parte das copas cultivadas e alta tolerância ao déficit hídrico.

Entre outros porta-enxertos utilizados no Brasil, citam-se a tangerina 'Cleopatra', o citrumelo 'Swingle' e o Poncirus trifoliata (Salva, 2001). Tais porta-enxertos vêm ganhando destaque, por apresentarem maior tolerância à 'Morte Súbita dos Citros' (MSC), uma nova doença detectada no Sudoeste de Minas Gerais e no Norte de São Paulo. A MSC, de etiologia ainda não determinada, vem afetando principalmente pomares de laranja-doce e de tangerinas enxertados sobre limão 'Cravo' (Fundecitrus, 2003).

A ocorrência da MSC tem acarretado a busca por novos portaenxertos, levando à baixa disponibilidade de sementes, especialmente de citrumelo 'Swingle' (Fundecitrus, 2003), híbrido entre pomelo Duncan (Citrus paradisi) e Trifoliata (Poncirus trifoliata L. Raf.), que é considerado tolerante à gomose (Phytophthora sp.), ao nematóide dos citros (Tylenchulus semipenetrans), à tristeza dos citros, ao declínio, à exocorte, à xiloporose e a baixas temperaturas. A qualidade dos frutos de laranjeiras enxertadas em citrumelo 'Swingle' é considerada ótima, com elevada concentração de sólidos solúveis e alto rendimento industrial na extração de suco (Pompeu Júnior, 1991).

A micropropagação através da cultura de ápices caulinares e gemas axilares permite a obtenção de um grande número de plantas geneticamente iguais em curto espaço de tempo, partindo de uma única semente, desde que sejam fornecidas condições ideais, principalmente no que diz respeito ao meio de cultura (Pasqual \& Ando, 1989a). Buscouse, neste trabalho, micropropagar o citrumelo 'Swingle', através de cultura de gemas axilares de plântulas germinadas in vitro, visando a alternativas técnicas viáveis para aumentar a disponibilidade de plantas desse porta-enxerto para produção de mudas de citros.

\section{MATERIALEMÉTODOS}

Frutos de citrumelo 'Swingle' foram colhidos de árvores da coleção experimental de citros da Escola Superior de Agricultura "Luiz de Queiroz", Universidade de São Paulo, em Piracicaba-SP, com localização de $22^{\circ} 43^{\prime}$ S, $43^{\circ} 38^{\prime}$ 'W e 540 metros de altitude. Após a extração das sementes, procederam-se a secagem e retirada do integumento. A desinfestação foi realizada em solução de água deionizada:hipoclorito de sódio (2,5\% de cloro ativo), na proporção de $3: 1$, durante 20 minutos, seguida de três lavagens em água esterilizada. As sementes foram, a seguir, incubadas em tubos de ensaio ( $25 \times 150$ $\mathrm{mm}$ ), contendo $10 \mathrm{~mL}$ do meio de cultura MT (Murashige \& Tucker, 1969) suplementado com $25 \mathrm{~g} \mathrm{~L}^{-1}$ de sacarose, $4 \mathrm{~g} \mathrm{~L}^{-1}$ de Phytagel (Sigma, USA) e pH ajustado para 5.8.

Gemas axilares foram excisadas após seis semanas de incubação e germinação das sementes (Figura 1a), sob fotoperíodo de 16 h, e então inoculadas em meio MS (Murashige \& Skoog, 1962) suplementado com as combinações de 6-benzilaminapurina (BAP) $\left(0,0 ; 0,5 ; 1,0\right.$ e $\left.1,5 \mathrm{mg} \mathrm{L}^{-1}\right) \mathrm{e}$ ácido naftaleno acético (ANA) $\left(0,0 \mathrm{e} 0,5 \mathrm{mg} \mathrm{L}^{-1}\right)$, em um esquema fatorial 4 $\mathrm{x} 2$, inteiramente casualizado, com oito repetições, sendo 5 gemas por parcela, em caixas Magenta ${ }^{\mathrm{TM}}$ (Figura 1b). $\mathrm{O} \mathrm{pH}$ do meio foi ajustado para 5.8 e solidificado com ágar $\left(8 \mathrm{~g} \mathrm{~L}^{-1}\right)$. O material foi incubado sob um regime de 16 horas de luz a $27^{\circ} \mathrm{C}$. Após 60 dias da incubação, avaliou-se o número de brotações/gema com mais de $1 \mathrm{~cm}$ de altura (Figura 1d).

\footnotetext{
${ }^{1}$ (Trabalho 133/2004). Recebido: 15/10/2004. Aceito para publicação: 19/04/2005.

2 Aluno de Graduação, Departamento de Produção Vegetal, USP/ESALQ.

${ }^{3}$ Doutorando em Fitotecnia, bolsista CAPES , Departamento de Produção Vegetal, USP/ESALQ.

${ }^{4}$ Professor Associado, Departamento de Produção Vegetal, USP/ESALQ, C.P. 09, CEP 13418-900, Piracicaba-SP. Autor correspondente. famourao@esalq.usp.br

${ }^{5}$ Professora Associada, Laboratório de Biotecnologia Vegetal, USP/CENA.
} 


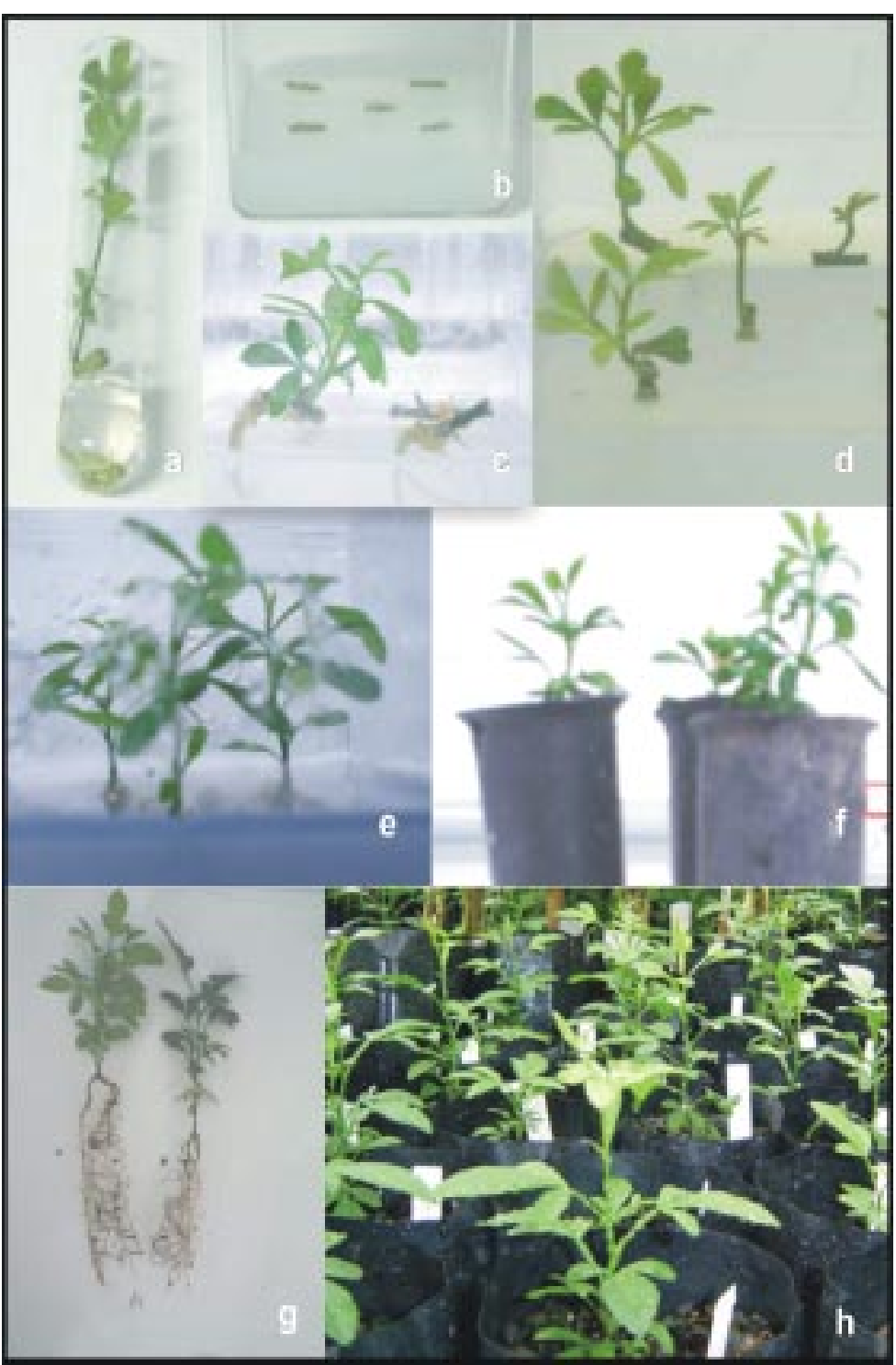

FIGURA 1 - Etapas da micropropagação do citrumelo ‘Swingle’: a) plântula germinada in vitro na luz; b) incubação dos explantes com gemas axilares; c) presença de raízes nos explantes em meio de cultura com alta concentração de ANA; d) brotações em meio de cultura sem adição de reguladores vegetais; e) enraizamento das brotações em meio RMAN; f) início da aclimatização dos brotos na sala de luz; g) parte aérea e radicular das plantas antecedendo o transplante definitivo; h) vista geral das plantas aclimatizadas em casa de vegetação.

Os brotos com mais de $1 \mathrm{~cm}$ de altura, obtidos das gemas axilares, foram excisados e transferidos para frascos Magenta $^{\mathrm{TM}}$ (Figura 1e) contendo meio de cultura RMAN (Grosser \& Gmitter Jr, 1990). O delineamento experimental foi o inteiramente casualizado, com seis repetições e quatro brotações por parcela, procurando-se controlar a origem das brotações em relação ao experimento inicial de indução de brotações. O material foi incubado sob regime de 16 horas de luz, a $27^{\circ} \mathrm{C}$, por 30 dias.

As brotações enraizadas foram transferidas para tubetes plásticos $(30 \times 120 \mathrm{~mm})$, contendo substrato Plantmax ${ }^{\mathrm{TM}}$ autoclavado (Figura 1f) e cobertas com sacos plásticos umedecidos, formando uma câmara úmida. Após 30 dias, as plantas foram retiradas dos tubetes (Figura 1g) e transplantadas para sacolas plásticas e mantidas em casa de vegetação (Figura 1h), onde receberam tratos culturais adequados para a produção de porta-enxerto cítrico. Antecedendo ao transplante, avaliou-se o desenvolvimento das plantas, que consistiu na contagem do número de pares de folhas e na aferição $(\mathrm{cm})$ do comprimento das raízes e da altura das plantas.

Os dados foram analisados por análise de variância, com comparação das médias pelo teste de Tukey. Os dados do número de brotações, em relação às concentrações de BAP, foram submetidos à regressão.

\section{RESULTADOSE DISCUSSÃO}

O número médio de brotações não foi influenciado pelas diferentes concentrações de ANA, nem para a interação BAP x ANA (dados não apresentados). Por outro lado, influência significativa foi observada para as diferentes concentrações de BAP, sendo que a ausência desse regulador vegetal resultou em baixa produção de brotos. Altas concentrações de auxina acarretaram enraizamento dos explantes (Figura 1c).

Segundo projeção teórica da equação apresentada (Figura 2), infere-se que maior número de brotos de 'Swingle' seriam obtidos na concentração de $0,89 \mathrm{mg} \mathrm{L}^{-1}$ de BAP, notando-se ainda uma tendência de redução nas concentrações superiores. Pasqual \& Ando (1989b) também observaram redução no estímulo às brotações de gemas axilares de Poncirus trifoliata em meios com concentrações de BAP superiores a 1 mg L ${ }^{-1}$, mesma observação feita por Al-Khayri \& Al-Bahrany (2001) em C. aurantifolia. A ausência de citocinina no meio de cultura propiciou um reduzido número de brotos por gema, mesmo relato feito por Pasqual e Ando (1989a) micropropagando C. sinensis, Al-Khayri \& Al-Bahrany (2001) em ensaios com C. aurantifolia, e Pereira et al. (1995) em espinheira santa (Maytenus ilicifolia). Mohanty et al. (1998) também relataram a importância da citocinina na indução de brotações de $C$. sinensis.

Dois meses após incubação dos brotos para enraizamento, retiraram-se os mesmos do meio de cultura e efetuou-se a contagem do total de enraizados por tratamento, mantendo-se os tratamentos do experimento de indução de brotos e calculando-se a percentagem de enraizamento (Tabela 1).

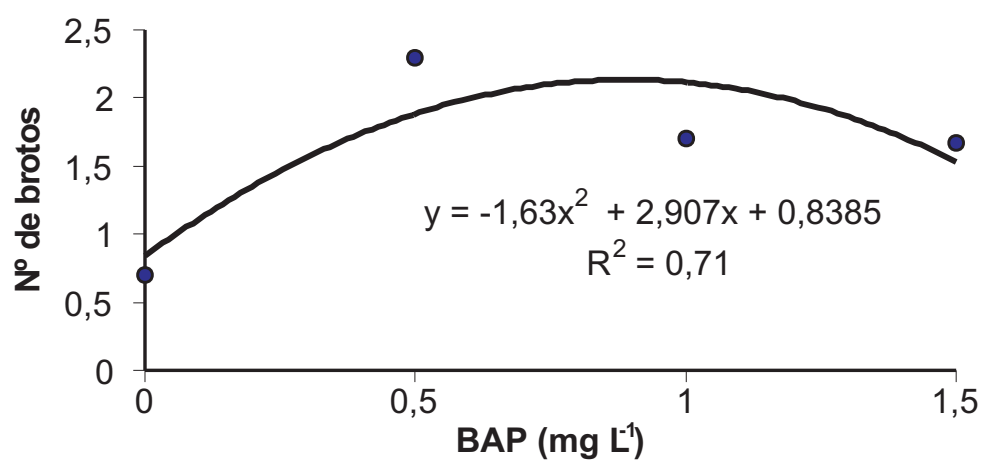

FIGURA 2 - Efeito do BAP no número médio de brotações de gemas axilares de citrumelo 'Swingle' (Piracicaba - SP, 2004)

TABELA 1 - Percentagem média de enraizamento dos brotos em função da concentração de BAP no meio de indução (PiracicabaSP, 2004)

\begin{tabular}{cc}
\hline Concentrações de BAP & $\begin{array}{c}\text { Percentagem média de } \\
\text { enraizamento dos brotos }\end{array}$ \\
\hline 0,0 & $50,0 \mathrm{a}$ \\
0,5 & $45,0 \mathrm{a}$ \\
1,0 & $55,0 \mathrm{a}$ \\
1,5 & $25,0 \mathrm{~b}$ \\
\hline $\mathrm{CV}(\%)$ & 14,65 \\
\hline
\end{tabular}

Médias seguidas de mesma letra não diferem entre si, pelo teste de Tukey $(\mathrm{P}<0,05)$

O objetivo do trabalho foi micropropagar o citrumelo 'Swingle' via gemas axilares, e para isso utilizou-se do meio de cultura padrão para o enraizamento de citros. Desta forma, não se observaram diferenças quanto ao número de brotos enraizados. Exceção é observada apenas para os brotos oriundos de tratamento com $1,5 \mathrm{mg} \mathrm{L}^{-1}$ de BAP, no meio de indução de brotação, os quais apresentaram baixa percentagem de enraizamento. 
TABELA 2 - Número médio de pares de folhas, comprimento médio das raízes e altura média das plântulas em função da concentração de BAP no meio de indução (Piracicaba-SP, 2004)

\begin{tabular}{|c|c|c|c|}
\hline $\begin{array}{c}\text { Concentrações de BAP } \\
-----\mathrm{mg} \mathrm{L}^{-1}-----\end{array}$ & Comp. médio das raízes & $\begin{array}{c}\text { Altura média das plântulas }(\mathrm{cm}) \\
\text {-------cm------ }\end{array}$ & $\begin{array}{l}\mathrm{N}^{\circ} \text { médio de } \\
\text { pares de folhas }\end{array}$ \\
\hline 0,0 & $13,75 \mathrm{a}$ & $4,6 \mathrm{a}$ & $5,1 \mathrm{a}$ \\
\hline 0,5 & $10,83 \mathrm{bc}$ & $2,7 \mathrm{ab}$ & $3,4 b$ \\
\hline 1,0 & $13,20 \mathrm{ab}$ & $2,4 \mathrm{~b}$ & $3,9 \mathrm{ab}$ \\
\hline 1,5 & $8,55 c$ & $2,4 b$ & $4,0 \mathrm{ab}$ \\
\hline $\mathrm{CV}(\%)$ & 7,42 & 16,7 & 8,82 \\
\hline
\end{tabular}

Médias seguidas de mesma letra não diferem entre si, pelo teste Tukey $(\mathrm{P}<0,05)$

A concentração mais alta de citocinina no experimento inicial de indução de brotação proporcionou brotos menores e menos vigorosos o que pode ter resultado em menor poder de enraizamento. Contrariamente ao resultado obtido in vitro quanto ao número médio de brotos por explante, quando se avaliou o desenvolvimento vegetativo dos mesmos, observou-se que os advindos de tratamento com menores concentrações de reguladores foram os mais vigorosos e, desenvolveram-se mais rapidamente (Tabela 2). Esse fato pode ser explicado pela provável falta de competição entre os brotos no início do desenvolvimento, pois as menores concentrações de BAP induziram menor número de brotos, conforme já mencionado. Observações semelhantes foram constatadas em Citrus aurantifolia (Al-Khayri \& Al-Bahrany, 2001).

Os resultados deste trabalho sugerem um protocolo para micropropagação de citrumelo 'Swingle' através de gemas axilares extraídas de plântulas germinadas in vitro (Figura 3).

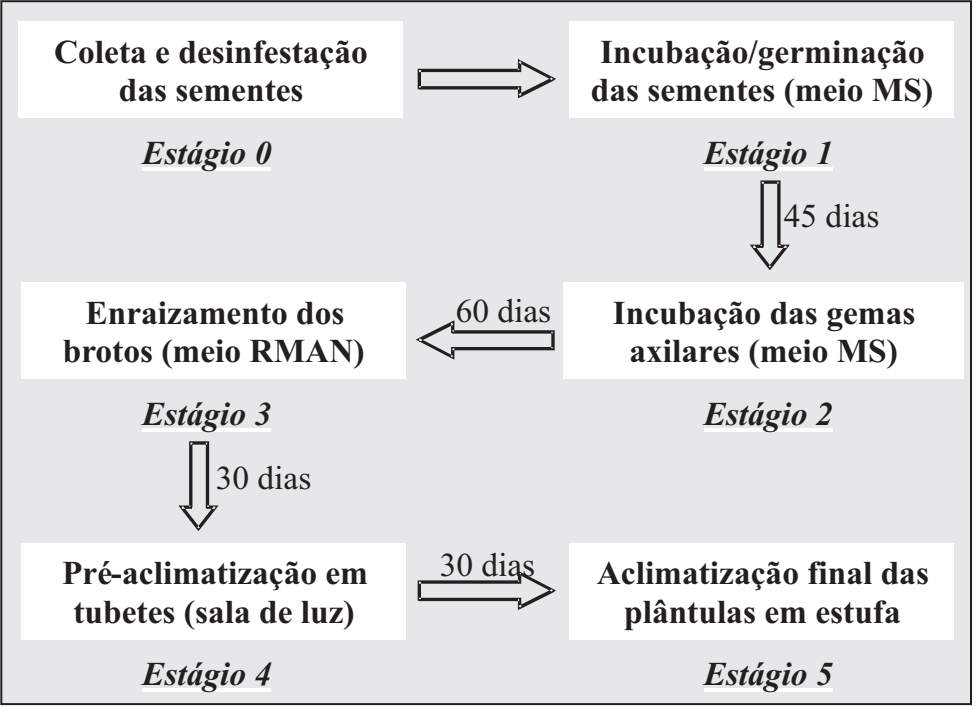

FIGURA 3 - Fluxograma ilustrativo contendo os estágios da micropropagação do citrumelo 'Swingle' via gemas axilares.

\section{CONCLUSÕES}

1. A micropropagação de citrumelo 'Swingle' pelo cultivo in vitro de gemas axilares é processo possível e viável.

2. A adição de BAP ao meio de cultura influenciou positivamente na indução de brotações.

3. Brotações provenientes de meio de cultura com concentrações menores de reguladores apresentaram desenvolvimento vegetativo superior.

\section{REFERÊNCIAS}

AL-KHAYRI, J.M.; AL-BAHRANY, A.M. In vitro micropropagation of Citrus aurantifolia (lime). Current Science, Bangalore, v.81, n.9, p.1242-1246, 2001.

AMORIM, E.P.R. Controle biológico de Phytophthora parasitica Dastur e Phytophthora citrophthora (Smith e Smith) Leonian em plântulas de citros. 1997. 113f. Tese (Doutorado) - Faculdade de Ciências Agrárias, Universidade Estadual Paulista "Júlio de Mesquita Filho", Botucatu, 1997.

FUNDECITRUS. Manual morte súbita dos citros. Araraquara: Fundecitrus, 2003. 11p.

GROSSER, J.W.; GMITTER JUNIOR, F.G. Protoplast fusion and Citrus improvement. Plant Breeding Reviews, New York, v.8, p.339-374, 1990.

MOHANTY, S.; DEKA, P.C.; BHATTACHARRYA, S. Micropropagation of Citrus sinensis cultivar Musambi. Indian Journal of Agricultural Sciences, New Delhi, v. 68, n.2, p.113-116, 1998.

MURASHIGE, T.; SKOOG, F. A revised medium for rapid growth and bioassays with tobacco tissue cultures. Physiologia Plantarum, Copenhangen, v.15, p.473-497, 1962.

MURASHIGE, T.; TUCKER, D.P.H. Growth factor requirement of citrus tissue culture. In: INTERNATIONAL CITRUS SYMPOSIUM, 1., 1969, Riverside. Proceedings... Riverside: University of California, 1969. p.1155-1169.

PASQUAL, M.; ANDO, A. Micropropagação da laranja 'Valência' através da cultura de gemas axilares in vitro. Pesquisa Agropecuária Brasileira, Brasília, v.24, n.6, p.723-726, 1989a.

PASQUAL, M.; ANDO, A. Micropropagação de 'Trifoliata' através de cultura de gemas axilares in vitro. Pesquisa Agropecuária Brasileira, Brasília, v.24, n.2, p.217-220, 1989b.

PEREIRA, A.M.S.; MORO, J.R.; CARDEIRA, R.M.M.; FRANÇA, S.C. Effect of phytoregulators and physiological characteristics of the explants on micropropagation of Maitenus ilicifolia. Plant Cell, Tissue and Organ Culture, Dordrecht, v.42, p.295-297, 1995.

POMPEU JÚNIOR, J. Porta-enxertos. In: In: RODRIGUEZ, O.; VIEGAS, F.; POMPEU JÚNIOR, J.; AMARO, A.A. (Eds.). Citricultura brasileira. Campinas: Fundação Cargill, 1991.p.265-280.

POMPEU JÚNIOR, J. Rootstocks and scions in the citriculture of de São Paulo State. In: INTERNATIONAL CONGRESS OF CITRUS NURSERYMEN, 6., 2001, Ribeirão Preto. Proceedings... Ribeirão Preto: EECB/Fundecitrus, 2001.p. 75-82.

ROSSETTI, V. Clorose variegada dos citros (CVC). In: RODRIGUEZ, O.; VIEGAS, F.; POMPEU JÚNIOR, J., AMARO, A.A. (Coord.). Citricultura brasileira. Campinas: Fundação Cargill, 1991. v.2, p.715-720.

SALVA, R. Citrus tree production in Brazil. In: INTERNATIONAL CONGRESS OF CITRUS NURSERYMEN, 6., 2001, Ribeirão Preto. Proceedings... Ribeirão Preto: EECB/Fundecitrus, 2001. p. 11-16. 